\title{
Sense Relations in Restrictive Appositives
}

\author{
Hero Gunawan*, Puspita Sari \\ Department of English, Faculty of Languages, Widyatama University, Indonesia
}

Copyright $\bigcirc 2019$ by authors, all rights reserved. Authors agree that this article remains permanently open access under the terms of the Creative Commons Attribution License 4.0 International License

\begin{abstract}
Restrictive appositives are constituents that cannot be separated from the anchor. However, this type of appositive can be analyzed both syntactically and semantically. In this article, syntactically, restrictive appositives are viewed from the two perspectives: the features and the construction. Semantically, restrictive appositives are viewed from the sense relations both syntagmatic and paradigmatic ones. Therefore, this research serves three aims: 1) to explain the features of restrictive appositives, 2) to analyse the construction of restrictive appositives, and 3) to explain the sense relations built in the anchor and appositive both in presentia relation (syntagmatic relation) and in absentia relation (paradigmatic relation). The data sources are taken from three English printed media: 1) daily news The Jakarta Post, 2) weekly magazine TIME, and 3) monthly magazine Reader's Digest. The Data are analysed through employing the method of qualitative research, that is, the method producing descriptive data, both written and oral data. To analyse such descriptive data, the distributional method of analysis with the following techniques is used: deleting, extracting, and intruding. The results indicate that: 1) restrictive appositives are full-strict, full-weak, partial-strict, and partial-weak, in features; 2) the appositional constructions, in which there are restrictive appositives, are formed on the noun-based constituents, namely noun phrase and noun clause both finite and nonfinite in nature; 3) the appositional construction has two sense relations, that is, syntagmatic and paradigmatic ones. By syntagmatic relation, appositional construction has syntactic linier relatedness. By paradigmatic relation, the constituents in the construction of apposition have sense closeness so as they are substitutable.
\end{abstract}

Keywords Restrictive Appositives, Anchor, Sense Relation, Syintagmatic, Paradigmatic

\section{Introduction}

Appositive, as suggested by Djajasudarma (2006), is a part of linguistic studies. Appositive as a research object, constructionally, are mainly part of syntactic study. Therefore, appositive, both in the form of phrases and clauses, can be analysed either from the syntactic viewpoint or from the semantic viewpoint. From the two points of view, this study is expected to provide comprehensive understanding dealing with appositive both from the construction and sense relations in it.

The central attention of this article is restrictive appositive viewed from the two perspectives: syntactic and semantic ones. The syntactic perspective will focus on how appositional construction is formed, while the semantic perspective will focus on the sense relations between appositive and its anchor. The data used as the samples of the analysis are taken from three types of printed media: the daily news The Jakarta Post, the weekly magazine Time and the monthly magazine Reader's Digest. The academic reasons for choosing such the data sources are, as suggested by Alwi (1992:25), that: 1) written data indicate more consistent language use in nature compared with the oral/spoken data both interms of sentence structure and in terms of vocabularies used, 2) written data tend to be the so called standard language. Besides, the use of English in printed media tends to be standar, natural, and popular.

From the brief background above, the problems under discussion can simply be formulated in three research questions:

1) What is/are the nature of restrictive appositive found in the research data?

2) How is the appositional construction formed found in the research data?

3) What is the sense relations between appositive and its anchor in the appositional constructions found in the research data?

The three problems are approached through employing relevant linguistic theories, namely: the first and second problems can be handled by using related syntactic theories covering appositives as the 'main course' of study, grammatical hierarchies, and syntactic function underlying the data analysis. The theories related to appositive will carefully disussed ranging from the types of appositive to the general concept of appositive as 
suggested by Quirk et al. (1999).

The third problem is approached through using the semantic theories particularly the ones that are related to sense relations in the appositional constructions. The theories related to these semantic aspects are taken from Quirk et al. (1999), Cruse (2000), de Vries (2002), Cowan (2008), dan Heringa (2012), Anyi (2017), Cao (2018), Chianese, (2018), Anwar, (2018).

\section{Methodology}

This research deals with the particular aspects of linguistics providing careful and systematic descriptions, namely, natures of appositive, appositional constructions, and sense relations. Therefore, the method employed in this research must be clear and systematic, as suggested by Djajsudarma (2006), saying that method is careful, systematic ways of thinking to obtain scientific objectves in the development of science; systemic techniques to conduct scientific activities of which the objectives have been determined.

This research is descriptive in nature because the data used are not evaluated or judged to be true-false but they are viewed as the true phenomena as they are, ...determines and describes the way the things are through collecting data to answer questions about the current subject of study (Gay, 2009: 601). It is in line with Suryabrata's (2010: 75) notions, saying that the objectives of descriptive research are to make systematic, factual, and accurate description regarding the facts and certain accumulated natures (Ahmed, Umrani, Qureshi \& Sarmad, 2018; Ali \& Haseeb, 2019; Haseeb, Abidin, Hye, \& Hartani, 2018; Haseeb., 2019; Suryanto, Haseeb, \& Hartani, 2018).

The method used in this research is qualitative research method, that is, the method producing descriptive data, both written and oral data (Djajsudarma, 2006; Davidovitch \& Belichenko, 2018; De, et.al. 2018). To analyse such descriptive data, the distributional method of analysis with the following techniques is used: deleting, extracting, intruding, and substituting (Sudaryanto, 2015; Dandan \& Marques, 2017; Cihan, 2018; Çoban \& Yildirim, 2018).

Based on this method, the author depicts the existing phenomena explicitely covering collecting and identifying the data, defining, and explaining the problems naturally (Seliger, 1989: 125), and as carefully and comprehensively as possible (Fraenkel, 1990:11). This method is not dedicated to find out the relationship among variables or causalities (Lodico, 2006:173). This descriptive research enables to do comparison between one context and another (Gay, 2009: 376).

\section{Literature Review}

When reading, it is common for readers to find appositives in English sentences or in a text in a broader context. The existence of appositives is to provide additional information and limitation so as the message I the sentence become clear. Quirk et al. (1999:1300), in relation to the definition of appositive, explaining that apposition is primarily, and typically, a relation between noun phrases. Hence, appositives have close relatedness with noun phrases. Therefore, it is obvious that appositives, in general, indicate the existence of coordination to the antecedent (de Vries, 2002).

The coordination between appositive and its antecedent is called, by Heringa (2012:1), appositional construction. Then it is described that in the appositional construction, there are two constituents: anchor and appositive itself as shown in the illustration below.

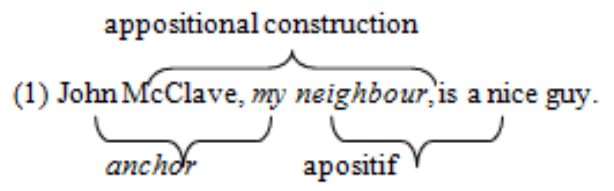

The first constituent John McClave in that construction is called anchor as the core element, while the second constituent my neighbour is called appositive. This indicates that in appositional construction, there are two elements having the same reference, the same sintactic function, and grammatical acceptability.

\subsection{Restrictive Appositive $V s$ Nonrestrictive Appositive}

It is called restrictive appositive if the reference is identified through the provided explanation in the appositive itself, and this, at the same time, indicates the existence of limitation of the reference from the anchor, for example:

(2) Mr Campbell the lawyer was here last night.

The construction puts Mr Campbell as the anchor, and the lawyer as appositive. In written language, this kind of appositive does not use the punctuation comma (,). The noun phrase the lawyer cannot be omitted, and it becomes the definer of any other Mr Campbell that we know. Therefore, it is obvious that restrictive appositive construction, in the constituents (anchor and appositive), has the same unit meaning.

Unlike restrictive appositive construction, in nonrestrictive appositive construction, the two constituents (anchor and appositive) have independent meaning, and the information in the appositive is only additional in nature, as in the following:

(3) Mr Campbell, a lawyer, was here last night.

(3a) A lawyer was here last night.

Sentence (3) indicates that $\mathrm{Mr}$ Campbell as the anchor, and a lawyer as the appositive. In written language, this kind of appositive uses the punctuation comma (,). The noun phrase a lawyer can be ommisable because it is only additional information, and it has independent meaning as 
shown in (3a).

Therefore, from the two samples above (2) and (3), it can be identified that the indicator of restrictive appositive is the existence of the same unit of meaning which cannot be separated each other. In other words, the appositive becomes the definer of the anchor. On the contrary, the indicator of nonrestrictive appositive is that the two constituents have independent meaning.

\subsection{Restrictive Appositive}

Since appositives have four basic features, namely, full, partial, strict, and weak as shown in Table 3.1 below, restrictive appositives have also four types.

Table 3.1. Basic Features of Appositive and Its Indicators

\begin{tabular}{|c|l|l|}
\hline NO & FEATURE & \multicolumn{1}{|c|}{ INDICATOR } \\
\hline 1 & Full & $\begin{array}{l}\text { Having grammatical acceptability, the same } \\
\text { syntactic function, and the same referent } \\
\text { (coreference) }\end{array}$ \\
\hline 2 & Partial & $\begin{array}{l}\text { Not fulfilling the requirements as the full } \\
\text { features }\end{array}$ \\
\hline 3 & Strict & $\begin{array}{l}\text { The two constituents (anchor and appositive) } \\
\text { have the same syntactic class }\end{array}$ \\
\hline 4 & Weak & $\begin{array}{l}\text { The two constituents (anchor and appositive) } \\
\text { have the different syntactic class }\end{array}$ \\
\hline
\end{tabular}

From the Table 3.1 above, the four features of restrictive appositive can be derived: 1) full-strict restrictive appositive, 2) full-weak restrictive appositive, 3) partial-strict restrictive appositive, and 4) partial-weak restrictive appositive.

\section{1) Full-Strict Restrictive Appositive}

The sample of this kind of appositive can be seen in (4). It is categorized into full because of being grammatically acceptable despite the fact that one of the two constituents (anchor and appositive) is omitted as in (4a) and (4b). The other features of being full are that the two constituents have the same syntactic functions and the same referents (coreference) as in (4c).

(4) My friend Anna was here last night.

(4a) Anna was here last night. (acceptable, subject)

(4b) My friend was here last night. (acceptable, subject)

(4c) Anna is my friend. (coreferential)

Sentence (4) is also categorized into strict because the two constituents, the anchor my friend and the appositive Anna, have the same syntactic class, that is noun phrase. Being restrictive, the two constituents (anchor my friend and appositve Anna) have the same unit of meaning, and cannot be separated each other.

\section{2) Full-Weak Restrictive Appositive}

The sample of this kind of appositive can be seen as in (5). It is categorized into full because of being grammatically acceptable despite the fact that one of the two constituents (anchor and appositive) is omitted as in (5a) and (5b). The other feature of being full is that the two constituents have the same syntactic functions and the same referents (coreference) as in (5c).

(5) The question whether to confess or not troubled the girl.

(5a) Whether to confess or not troubled the girl.

(5b) The question troubled the girl.

(5c) The question is whether to confess or not.

Sentence (5) is also categorized into weak because the two constituents, the anchor the question and the appositive whether to confess or not, have the different syntactic class (noun phrase and nonfinite clause). Being restrictive, the two constituents (the anchor the question and the appositve whether to confess or not) have the same unit of meaning, and cannot be separated each other.

\section{3) Partial-Strict Restrictive Appositive}

The sample of this kind of appositive can be seen in (6). It is categorized into partial because it does not meet the requirements as the full appositive, and as aforementioned in Table 3.1, there are three requirements to be the full appositive: 1) grammatical acceptability, 2) the same syntactic function, and 3) the same referent. Related to this sample, the requirement that cannot fullfilled is grammatical acceptability. Sentence (6) becomes ungrammatically acceptable when one of the two constituents (anchor and appositive) is omitted as in (6b) in spite of being grammatically acceptable as in (6a). The two other features of being full are that the two constituents 1) have the same syntactic functions (as subjects) as in (6a), and as in (6c) with simple correction and 2) have the same referents (coreference) as in (6d) with the simple correction.

(6) Next Saturday, financial expert Tom Timber will begin writing a weekly column on the national economy.

(6a) Next Saturday, Tom Timber will begin writing a weekly column on the national economy. (berterima)

(6b) *Next Saturday, financial expert will begin writing a weekly column on the national economy. (unacceptable)

(6c) Next Saturday, [the] financial expert will begin writing a weekly column on the national economy. (unacceptable)

(6d) Tom Timber is [a] financial expert.

Sentence (6) is also categorized into strict because the two constituents, the anchor financial expert and the appositive Tom Timber, have the same syntactic class, that is, a noun phrase. Being restrictive, the two constituents (anchor financial expert and appositve Tom Timber) have the same unit of meaning, and cannot be separated each other.

4) Partial-Weak Restrictive Appositive.

The sample of this kind of appositive can be seen as in (7). It is categorized into partial because it does not meet the requirements for being the full appositive, and as aforementioned in Table 3.1, there are three requirements to be the full appositive: 1) grammatical acceptability, 2) 
the same syntactic function, and 3) the same referent. Related to this sample, the requirement that cannot fullfilled is being coreferential (the same referents), the anchor his claim is considerd as a demand, while the appositive that he couldn't see the car is considered as a fact as in (7a) and (7b). The two other features of being full are that the two constituents 1) have the same syntactic functions (as subjects) as in (7a) and (7b), and 2) have the same grammatical acceptability as in (7a) and (7b).

(7) His claim that he couldn't see the car was unconvincing.

(7a) His claim was unconvincing. (as a subject, as a demand, as a noun phrase)

(7b) That he couldn't see the car was unconvincing. (as a subject, as a fact, and as a clause)

Sentence (7) is also categorized into weak because the two constituents, the anchor his claim and the appositive the fact that he couldn't see the car, have the different syntactic class (noun phrase and clause). Being restrictive, the two constituents (the anchor his claim and the appositive the fact that he couldn't see the car) have the same unit of meaning, and cannot be separated each other.

\subsection{Syntagmatic Sense Relations}

Syntagmatic sense relation is understood as the sense relation which occurs among constituents within the same sentence, particularly the sentence which holds the syntactic relatedness, (Djajasudarma, 2013: 141). Hence, it is obvious that sense realations focus more on syntactic relations in which the sense relations construct, for examples:

(8) The girl ran across the field. (normal and acceptable)

(8a) The girl sat across the field. (abnormal and unacceptable)

(8b) The smell ran across the field. (abnormal and unacceptable)

The combination of the prepositional phrase sat across in (8a), and the sebject and verb the smell ran in (8b) do not show the existence of syntactic relatedness.

\subsection{Paradigmatic Sense Relations}

Syntagmatic sense relation does not stand alone, it relates closely to paradigmatic sense relation. If syntagmatic sense relation is illustrated as a horizontal axis, then paradigmatic sense relation is as vertical one. Paradigmatic sense relation is a kind of sense relation of certain structural expressions which is operationally constructed through mechanism of choice (Djajsudarma, 2013: 113\&141). Because of this, paradigmatic sense relation is called in absentia sense relation, as shown in (9) below:
(9) He bought a bottle of liquid.

Conceptually, in English, anything that is drinkable is categorized into liquid so that the constituen liquid can be subtituted with any other names of drinking, e.g., milk, juice, beer, lemonade, brandy, and many other drinking names, for examples:

(9a) He bought a bottle of [milk, juice, beer, lemonade, brandy].

Therefore, construction (9) has paradigmatic (in absentia) sense relation since one of the constituents in it enables to experience the substitution process with any other words having the same concept.

\section{Result and Discussion}

With respect to the aforementioned features of the appositive in the appositional constructions and the relatedness between anchor and appositive, this analysis mainly focuss on 1) to which features the appositive belong, 2) the construction of apposition, and 3) the sense relations between anchor and appositive. Therefore, this analysis may uncover the features attached in appositives, how the appositional constructions are built, and what sense relations can be found between anchor and its appositive.

Data of appositionl constructions in which one of the constituents is restrictive appositive is understood that the two constituents (anchor and appositive) have the same unit of meaning. Four samples of the data related to the restrictive appositives are analysed. The four data (data 10 through 13) have certain features and contents.

(10) One in 5 women with breast calcifications ended up with coronary heart disease, says lead researcher $D r$. Peter Schnatz from the Reading Hospital and Medical Center in Pennsylvania.

Data (10) above is the appositive with the content of proper noun (personal) and this is classified into partial-strict restrictive appositive. It is categorized into partial because it does not meet the requirements for being the full appositive, and as aforementioned at Table 3.1, there are three requirements to be the full appositive: 1) grammatical acceptability, 2) the same syntactic function, and 3) the same referent. Related to this data, the requirement that cannot fullfilled is grammatical acceptability. Sentence (10) becomes ungrammatically acceptable when one of the two constituents (anchor and appositive) is omitted as in (10a) in spite of being grammatically acceptable as in (10b). The two other features of being full are that the two constituents 1) have the same syntactic functions (as subjects) as in (10a) with simple correction, and as in (10b), and 2) have the same referents (coreference) as in (10c) with the simple correction. 
(10a) * One in 5 women with breast calcifications ended up with coronary heart disease, says [the] lead researcher from the Reading Hospital and Medical Center in Pennsylvania.

(10b) One in 5 women with breast calcifications ended up with coronary heart disease, says Dr. Peter Schnatz from the Reading Hospital and Medical Center in Pennsylvania.

(10c) Dr. Peter Schnatz is [the] lead researcher.

Data (10) is also categorized into strict because the two constituents, the anchor lead researcher and the appositive Dr. Peter Schnatz, have the same syntactic class, that is, a noun phrase. Being restrictive, the two constituents (the anchor lead researcher the appositive $D r$. Peter Schnatz) have the same unit of meaning, and cannot be separated each other.

The appositional construction is formed from the two united constituents: the anchor and its appositive with the same grammatical hierarchy, that is, a noun phrase, and the position of the two constituents are in coexistent without punctuations as illustrated below.

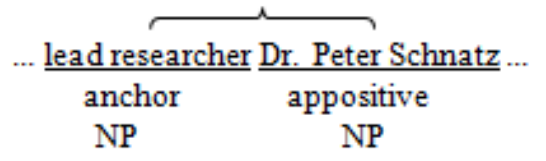

The appositive lead researcher in the appositional construction lead researcher Dr. Peter Schnatz has syntagmatic relation in the form of profession/position referring to a proper name (personal). The two constituents indicate syntactic closeness between profession/position and person.

Perceiving the existence of syntagmatic relation above, the appositive lead researcher in (10) enables to be replaced by another profession referred to a proper noun (personal). In other words, substitution process may occur in the syntactic coocurrence. The substitution process can be done through replacing the word researcher with another related word such as the word observer so we can have lead observer Dr. Peter Schnatz. Therefore, the appositive lead researcher has paradigmatic relation (in absentia) because there will be possible for doing the substitution process so that the sense relation made indicates the existence of syntactic closeness in the appositional construction. However, if the word researcher is replaced by the name of object such as computer, so as it becomes lead computer Dr Peter Schnatz, then such an appositional construction becomes abnormal.

(11) A few weeks after Greene woke from his coma, his sister Suzanne arrived for a visit.

Data (11) above is the appositive with the content of proper noun (personal) and this is classified into full-strict restrictive appositive. It is categorized into full because it has met the three criteria for being full appositive: 1) being grammatically acceptable despite the fact that one of the two constituents (anchor and appositive) is omitted as in (11a) and (11b); 2) having the same syntactic functions, i.e., as a subject; and 3) having the same referents (coreference) as in (11c).

(11a) A few weeks after Greene woke from his coma, his sister arrived for a visit.

(11b) A few weeks after Greene woke from his coma, Suzanne arrived for a visit.

Sentence (11) is also categorized into strict because the two constituents, the anchor his sister and the appositive Suzanne, have the same syntactic class, that is noun phrase. Being restrictive, the two constituents (anchor my friend and appositve Anna) have the same unit of meaning, and cannot be separated each other.

The appositional construction is formed from the two united constituents: the anchor and its appositive with the same grammatical hierarchy, that is, a noun phrase, and the position of the two constituents are in coexistent without punctuations as illustrated below.

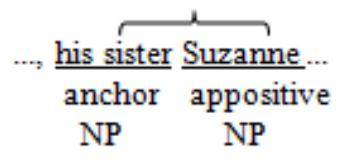

The appositive Suzanne in the appositional construction his sister Suzanne has syntagmatic relation in the form of proper name (personal namer) referring to a certain family relation. The two constituents indicate syntactic closeness between family relation and name of a person.

Perceiving the existence of syntagmatic relation above, the appositive Suzanne in (11) enables to be replaced by another name of person. In other words, substitution process may occur in the syntactic coocurrence. The substitution process can be done through replacing the name Suzanne with another related personal name such as the name Nancy so we can have his sister Nancy or even the phrase his sister can be replaced by another relevant family relation, for example, his daughter so as it becomes his daughter Suzanne. Therefore, the appositive his sister Suzanne has paradigmatic relation (in absentia) because there will be possible for doing the substitution process so that the sense relation made indicates the existence of syntactic closeness in the appositional construction. However, if the personal name Suzanne is replaced by nonpersonal name, or if the phrase his sister is replaced by other nonpersonal, it will become abnormal, for example, his computer Suzanne, or his sister Grammar.

(12) The fact that medical professionals in Malaysia are well-versed in English, Mandarin, Chinese dialects and Malay helps immensely in building a patient's level of comfort.

Data (12) above is the appositive with the content of person qualified in a profession, and this is classified into full-weak restrictive appositive. It is categorized into full 
because it has met the three criteria for being full appositive: 1) being grammatically acceptable despite the fact that one of the two constituents (anchor and appositive) is omitted as in (12a) and (12b); 2) having the same syntactic functions, i.e., as a subject; and 3) having the same referents (coreference) as in (12c).

(12a) The fact helps immensely in building a patient's level of comfort.

(12b) That medical professionals in Malaysia are well-versed in English, Mandarin, Chinese dialects and Malay helps immensely in building a patient's level of comfort.

Sentence (12) is also categorized into weak because the two constituents, the anchor the fact and the appositive that medical professionals, have the different syntactic class (noun phrase and clause). Being restrictive, the two constituents (the anchor the fact and the appositive that medical professional) have the same unit of meaning, and cannot be separated each other.

The appositional construction is formed from the two united constituents: the anchor and its appositive with the same grammatical hierarchy, that is, a noun phrase, and the position of the two constituents are in coexistent without punctuations as illustrated below.

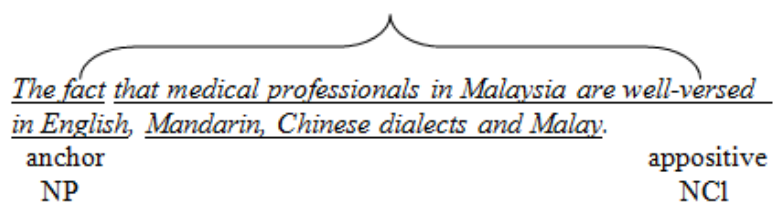

The appositive that medical professionals in Malaysia are well-versed in English, Mandarin, Chinese dialects and Malay in the appositional construction the fact that medical professionals in Malaysia are well-versed in English, Mandarin, Chinese dialects and Malay has syntagmatic relation in the form of person qualified in a profession referring to a certain reality (fact). The two constituents indicate syntactic closeness between professional person and a fact.

Perceiving the existence of syntagmatic relation above, the appositive that medical professional in Malaysia are well-versed in English, Mandarin, Chinese dialects and Malay in (12) enables to be replaced by another name of person. In other words, substitution process may occur in the syntactic coocurrence. The substitution process can be done through replacing the word professionals dan well-versed in the appositional construction the fact that medical professionals in Malaysia are well-versed in English, Mandarin, Chinese dialects and Malay can respectively be replaced with specialists and knowledgeable, so that it becomes the fact that medical specialists in Malaysia are knowledgeable in English, Mandarin, Chinese dialects and Malay. Therefore, the appositive that medical professionals in Malaysia are well-versed in English, Mandarin, Chinese dialects and Malayhis sister Suzanne has paradigmatic relation (in absentia) because there will be possible for doing the substitution process so that the sense relation made indicates the existence of syntactic closeness in the appositional construction.

However, if the word professional in the appositive is replaced by something that is nothing to do with person qualified in a profession such as mountain, so as it becomes the fact that medical mountains in Malaysia are well-versed in English, Mandarin, Chinese dialects and Malay, then such an appositional construction becomes abnormal.

(13) And that's one of the reasons why I talk about her.

Data (13) above is the appositive with the content of explanation of a cause, and this is classified into partial-weak restrictive appositive. It is categorized into partial because it does not meet the requirements for being the full appositive, and as aforementioned in section III, literature review, there are three requirements to be the full appositive: 1) grammatical acceptability, 2) the same syntactic function, and 3) the same referent. Related to this data, the requirement that cannot fullfilled is being coreferential (the same referents), the anchor one of the reasons is considerd as explanation of a cause as in (13a), while the appositive why I talk about her is considered as effect as in (13b). The other evidence that it is not coreferential is that the anchor and the appositive have no copulative relationship as shown in (13c). The two other features of being full are that the two constituents 1) have the same syntactic functions (as subject complement) as in (13a) and (13b), and 2) have the same grammatical acceptability as in (13a) and (13b).

(13a) And that's one of the reasons.

(13b) And that's why I talk about her.

(13c) One of the reasons is why I talk about her. (not coreferential)

Another additional illustration, through using imaginary data, for example: Your loyalty to me is one of the reasons why I love you. The content of reason is not why I love you, and why I love you is not the reason. The actual content of the reason of the question why I love you is your loyalty to me.

Sentence (13) is also categorized into weak because the two constituents, the anchor one of the reasonhe fact and the appositive why I talk about her, have the different syntactic class (noun phrase and clause). Being restrictive, the two constituents (the anchor one of the reasonhe fact and the appositive why I talk about her) have the same unit of meaning, and cannot be separated each other. This implies that there are more that one reasons related to the reason why, but the reason why in this context of data (13) is the reason why I talk about her (alasan tentang mengapa saya berbicara tentang dia). Therefore, such a specific reason is restrictive in nature, limiting one reason from any other reasons.

The appositional construction is formed from the two united constituents: the anchor and its appositive with the 
different grammatical hierarchy, i.e., noun phrase at the anchor, noun clause at the appositive. The position of the two constituents is in coexistent without punctuations as illustrated below.

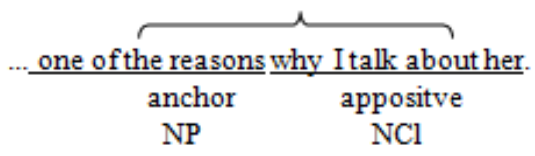

The appositive why I talk about her in the appositional construction one of the reasons why I talk about her has syntagmatic relation in the form of explanation of a cause referring to a reason. The two constituents indicate syntactic closeness between explanation of a cause and a reason.

Perceiving the existence of syntagmatic relation above, one of the elements, e.g. the word talk, in the appositive why I talk about her in (13) enables to be replaced by another related verb, for example the word discuss so that it becomes one of the reasons why I discuss about her. In other words, substitution process may occur in the syntactic coocurrence. However, if another element of the appositive, for example, the word why is replaced by any other clause connector such as where, so as it becomes one of the reasons where I talk about her, then such an appositional construction becomes abnormal.

\section{Conclusions and Suggestion}

\subsection{Conclusions}

After conducting the analysis on the previous section, it can be concluded that: 1) restrictive apposiives are full-strict, full-weak, partial-strict, and partial-weak, in features; 2) the appositional constructions, in which there are restrictive appositives, are formed on the noun-based constituents, namely noun phrase and noun clause both finite and nonfinite in nature; 3) the appositional construction has two sense relations, that is, syntagmatic and paradigmatic ones. By syntagmatic relation, appositional construction has syntactic linier relatedness. By paradigmatic relation, the constituents in the construction of apposition have sense closeness so as they are substitutable.

\subsection{Suggestion}

Based on the conclusion above, theoretically, it is obvious that the central attention of this research is on the appositional constructions which consist of anchor and noun-based appositives as an unseparated unit. Therefore, to facilitate the comprehensive understanding towards the complexity of appositives, it is necessary to create similar sustainable research. This sustainability is expected that effective and informative appositional constructions can provide good sentence-understanding which in turns, can help understand a discourse.

\section{REFERENCES}

[1] Anwar, M. N. (2018). Acquisition of Skills for Listening Comprehension: Barriers and Solutions. International Journal of English Language and Literature Studies, 7(3), 50-54.

[2] Anyi, E. M. E. (2017). The Role of Guidance and Counselling in Effective Teaching and Learning in Schools: The Cameroonian Perspective. International Journal of Educational Technology and Learning, 1(1), 11-15.

[3] Borjaars, Kersti, Kate Burridge. 2001. Introducing English Grammar. Arnold, London.

[4] Cao, M. (2018). The Cultivation of Cultural Consciousness in English Writing Teaching in China from the Perspective of Linguistics. Humanities and Social Sciences Letters, 6(1), $1-9$.

[5] Carnei, Andrew. 2007. Syntax: A Generative Introduction. 2nd Edition. Blackwell.

[6] Chianese, G. (2018). Promoting Students Active Citizenship: The Project Space. Asian Journal of Contemporary Education, 2(1), 1-7.

[7] Cihan, B. B. (2018). The Analysis of Problem-Solving Skills and Related Factors for Some Students Studying at Different Schools of Physical Education and Sports. Asian Journal of Education and Training, 4(4), 295-301.

[8] Çoban, O., \& Yildirim, M. (2018). The Comparison of High School Students' Level of Aggression Based on Demographic Features. Asian Journal of Education and Training, 4(4), 363-370.

[9] Coordination, False Free Relatives, and Promotion, Linguistic Inquiry 37(2), 229-270.

[10] Crystal, David. 2001. A Dictionary of Linguistics and Phonetics. Fourth Edition. Backwell

[11] Dandan, M. M., \& Marques, A. P. (2017). Higher education leadership and gender gap in Jordan. Asian Development Policy Review, 5(3), 131-139.

[12] Davidovitch, N., \& Belichenko, M. (2018). Facebook Tools and Digital Learning Achievements in Higher Education. Journal of Education and e-Learning Research, 5(1), 8-14.

[13] De, A. C., Kurian, S., Dinithi, M. K., Hareesh, N., \& Saira, P. (2018). Social Media for Higher Education: A Cross Sectional Study Among Teachers In India And Sri Lanka. Humanities and Social Sciences Letters, 6(4), 180-188.

[14] Education. McGraw-Hill Inc. New York.England. Longman. English. Language 40, 37-52.

[15] Fabb, Niggel. 1990. The Difference between English Restrictive and Nonrestrictive Relative Clauses, Journal of Linguistics 26, 57-78.

[16] Fraenkel, Jack R., Norman E. Wallen. 1990. How to Design and Evaluate Research in Education. 
[17] Heringa, Herman, 2010. A Multidominance Approach to Appositional Construction.Kebudayaan secara Linguistik. Sanata Dharma University Press. Yogyakarta. Longman.

[18] O'Grady, William, et al.1997. Contemporary Linguistics: An Introduction. London, Oxford: Oxford University Press. Publishers. Oxford, UK.

[19] Quirk, Randolf, et al.1999. A Conprehensive Grammar of the English Language. Research Project. Unpublished.

[20] Seliger, Herbert W. and Elana Shohamy. 1989. Second Language Research Method.

[21] Smith, Carlota S. 1964. Determiners and Relative Clauses in a Generative Grammar of English. Language 40:1,. 37-52.

[22] Sudaryanto, 2015. Metode dan Teknik Analisis Bahasa: Pengantar Penelitian Wahana

[23] Vries, Mark de. 2002. The Syntax of Appositive Relativization: On Specifying coordination, false free relatives and promotion, Linguistic Inquiry 37:229-70.

[24] Tayebi, S., Manesh, S., Khalili, M \& Sadi-Nezhad, S. (2019). The role of information systems in communication through social media.International Journal of Data and Network Science, 3(3), 245-268.

[25] Pourkhani, A., Abdipour, K., Baher, B \& Moslehpour, M. (2019). The impact of social media in business growth and performance: A scientometrics analysis.International Journal of Data and Network Science, 3(3), 223-244.

[26] Ahmed, U., Umrani, W. A., Qureshi, M. A., \& Samad, A. (2018). Examining the links between teachers support, academic efficacy, academic resilience, and student engagement in Bahrain. INTERNATIONAL JOURNAL OF ADVANCED AND APPLIED SCIENCES, 5(9), 39-46.

[27] Ali, A., \& Haseeb, M. (2019). Radio frequency identification (RFID) technology as a strategic tool towards higher performance of supply chain operations in textile and apparel industry of Malaysia. Uncertain Supply Chain Management, 7(2), 215-226.

[28] Haseeb, M., Abidin, I. S. Z., Hye, Q. M. A., \& Hartani, N. H. (2018). The Impact of Renewable Energy on Economic Well-Being of Malaysia: Fresh Evidence from Auto Regressive Distributed Lag Bound Testing Approach. International Journal of Energy Economics and Policy, 9(1), 269-275.

[29] Suryanto, T., Haseeb, M., \& Hartani, N. H. (2018). The Correlates of Developing Green Supply Chain Management Practices: Firms Level Analysis in Malaysia. International Journal of Supply Chain Management, 7(5), 316. 